emotion and relapse in depressed patients. British Journal of Psychiatry, 148, 642-647.

Leff, J. (1988) Psychiatry Around the Globe: A Transcultural View. Gaskell.

Mohit, A. (1999) Middle East culture: mental health and mental illness. In One World, One Language - Paving the Way to Better Perspectives for Mental Health (eds J. Lopez-Ibor, F. Lieh-Mak, H. Visotsky, et al). Hogrefe \& Huber.

Montero, I., Gomez-Beneyto, M., Ruiz, I., et al (1992) The influence of family expressed emotion on the course of schizophrenia in a sample of Spanish patients. British Journal of Psychiatry, 161, 217-222.

Okasha, A. (ed.) (1988) Okasha's Clinical Psychiatry. Anglo Egyptian Bookshop.

Okasha, A. (2000) The impact of Arab culture on psychiatric ethics. In Ethics Culture and Psychiatry. International Perspectives (eds A. Okasha, J. Arboleda-Florez \& N. Sartorius). American Psychiatric Press.

Okasha, A. \& Okasha, T. (2000) Notes on mental disorders in pharaonic Egypt. History of Psychiatry, 11, 413-424.
Okasha, A., El Akabawi, A., Synder, K., et al (1994) Expressed emotion, perceived criticism, and relapse in depression: a replication in an Egyptian community. American Journal of Psychiatry, 151, 1001-1005.

Ruiz, P. (ed.) (2000) Ethnicity and psychopharmacology. In Review of Psychiatry. Volume 19 (eds J. Oldham \& M. Riba). American Psychiatric Press.

United Nations Development Programme (2003) Human Development Report. Available at http://www.undp.org (last accessed 17 April 2007).

Vaughn, C. E. \& Leff, J. P. (1976) The influence of family and social factors on the course of psychiatric illness: a comparison of schizophrenic and depressed neurotic patients. British Journal of Psychiatry, 129, 125-137

World Psychiatric Association (1996) Declaration of Madrid on Ethical Standards for Psychiatric Practice. Approved by the General Assembly on 25 August 1996 and amended by the General Assembly in Yokohama, Japan, in August 2002. See http://wpanet.org/newhome/ about/ethic1.html (last accessed 17 April 2007).

\title{
Psychiatry in Germany
}

\section{Wolfgang Gaebel, Jürgen Zielasek and Ulrich Müller}

Department of Psychiatry and Psychotherapy, Heinrich-Heine-Universität, Rhineland State Clinics, Bergische Landstrasse 2, D-40629, Düsseldorf, Germany, email wolfgang.gaebel@uni-duesseldorf.de

ermany has an approximate area of $357000 \mathrm{~km}^{2}$. Its population is 82.526 million. The life expectancy at birth is 75.6 years for men and 81.6 years for women (World Health Organization, 2005). The proportion of gross domestic product allocated to the health budget is $10.8 \%$. The per capita total expenditure on health is $\$ 2820$ (international dollars here and below) and the per capita government expenditure on health is $\$ 2113$ (World Health Organization, 2005). A major factor in recent German history was reunification, which had a pronounced effect on the German healthcare system.

\section{History}

The term 'psychiatry' was coined by Johann Christian Reil in 1808. In the 19th century, German psychiatry began to develop into a scientific discipline under the influence of Wilhelm Griesinger (1817-68), who focused on a holistic but differentiated approach, covering biological and psychological methods. At the beginning of the 20th century, psychiatrists like Emil Kraepelin, Alois Alzheimer, Kurt Schneider and Carl Wernicke founded the basis of current psychiatric classification systems.

In the period of the National Socialists (1933-45), German psychiatry was partially instrumentalised for political purposes, especially for the programme of 'euthanasia'. This terrible period has been intensively analysed. The review by Seeman (2005) is a useful English introduction to this topic.
In the late 18th and early 19th century, large psychiatric institutions were founded, mainly outside the metropolitan areas. In the last part of the 20th century, the advent of psychopharmacotherapy and social psychiatry changed the picture of German psychiatry. Following the Psychiatrie Enquête report of 1975 (see under 'Mental health policy', below), many smaller psychiatric departments were set up in community hospitals but the total number of psychiatric hospital beds declined.

\section{Epidemiology}

The lifetime prevalence for any psychiatric disorder in Germany is $42 \%$ and the 12 -month prevalence rate is $31 \%$ for the adult population, not much different from the prevalence rate in the European Union (EU) as a whole, of $27 \%$ (Wittchen \& Jacobi, 2005). In Germany, only about 25\% of the population with a mental illness are in contact with mental health services, compared with $26 \%$ in the EU. Mental disorders are responsible for about $40 \%$ of all sick leave from work and $28 \%$ of all early retirements (Roth-Sackenheim, 2005). Mental disorders comprise the only growing group of disorders among all cases and days of sick leave in Germany, with an increase of approximately 70\% from 1994 to 2004 (DAK Gesundheitsreport, 2006).

There are about 55000 general practitioners in Germany. Given the 12-month prevalence rate of mental disorders in Germany of $31 \%$, there should be, annually, some 24 million 
people presenting with mental disorders, but general practitioners treat only about 10 million patients with mental disorders per year.

\section{Mental health policy}

In 1975 a Federal Commission of the Bundestag submitted a report (Psychiatrie Enquête) about the situation of psychiatry in Germany. The Commission defined the targets of a reform of psychiatry. The number of psychiatric hospital beds was reduced from 118000 in 1970 to 56392 in 1998 . The number of psychiatric hospitals decreased from 216 in 1994 to 195 in 1998 (Fritze et al, 2005). There was a considerable increase in the provision of community-based care as part of the psychiatric reforms. The involvement of family members and former patients gained more importance.

Several laws and regulations govern psychiatric medicine in Germany, with the most important being the state laws concerning forensic psychiatry and the federal ordinance determining the staffing of psychiatric hospitals. Furthermore, there is federal support for the prevention of addiction, and the German Health Ministry has issued an agenda regarding addiction research and management, with an emphasis on prevention.

In 1996, the World Psychiatric Association (WPA) started the Global Programme against Stigma and Discrimination because of Schizophrenia - 'Open the Doors' (Sartorius \& Schulze, 2005). In 1999, this public education programme was established in Germany and is now being implemented successfully in six project centres nationally. The National Programme to Reduce Stigma of Mental Disorders (chaired by Professor W. Gaebel) is an initiative of the German Society for Psychiatry, Psychotherapy and Nervous Diseases (DGPPN) and a non-governmental organisation, 'Open the Doors' (Baumann \& Gaebel, 2006).

There is no federal mental health act.

\section{Organisation of mental health services}

Mental health services in Germany are mainly community based. In-patient services are provided by university hospitals, state or local hospitals. Out-patient psychiatric services are mainly provided by private practitioners and hospital out-patient departments. In addition, specialised psychiatric out-patient services are arranged by local welfare organisations.

\section{Medical education}

Undergraduate medical education in Germany includes a 4-month course in psychiatry and psychotherapy. Although it is a separate medical specialty in Germany, child and adolescent psychiatry is often taught within the general psychiatry course. For historical reasons, psychosomatic medicine is a separate clinical specialty. However, the topics which are found under the heading 'psychosomatic medicine' in AngloAmerican countries are found within the general psychiatry curriculum in Germany. Medical students in their final (sixth) year of undergraduate medical school may choose a 4-month elective in psychiatry as one of three clinical specialties in which they receive specialist training.

Postgraduate medical education, to become a boardcertified psychiatrist, comprises 5 years of full-time employment in a psychiatric hospital, including 1 year in neurology.

Clinical psychiatrists need to participate in continuing medical education (CME) to achieve a minimum of $250 \mathrm{CME}$ credit points within each 5-year term.

Forensic medicine has been established since 2004 as the only psychiatric clinical subspecialty in Germany.

Psychotherapy is part of the compulsory clinical training in the specialty fields of 'psychiatry and psychotherapy', 'psychosomatic medicine and psychotherapy' and 'child and adolescent psychiatry'. Board certification requires knowledge in psychotherapy in all these specialties. Medical doctors who have obtained one of these specialty certifications may additionally acquire a further specialisation in psychoanalysis. Additional board certifications may be obtained by any medical doctor in Germany in the field of addiction disorders, and by any already specialised medical doctor (in any field) or psychologist in the field of psychotherapy.

\section{Psychiatric workforce}

Care for psychiatric patients in Germany is mainly centred on in- and out-patient settings in hospitals and private practices. In addition, rehabilitation programmes, sheltered workplaces and day-care facilities play a large role. Psychosocial counselling is also provided by the states, municipalities, churches and private facilities.

There are about 13800 specialists in the fields of 'psychiatry and psychotherapy', including the former specialisation in nervenheilkunde (nervous disorders). About 4500 psychiatrists in private practice are treating approximately 2.5 million patients per year. Thus, a large proportion of Germans may not have the necessary contact with the mental health system. The results of some surveys indicate that many patients with psychiatric diagnoses are not treated by psychiatrists, but by general practitioners or psychologists.

There are 7.5 psychiatric beds per 10000 population (4.5 in mental hospitals and 3.0 in general hospitals). The number of psychiatrists per 100000 population is 2.9 (World Health Organization, 2005).

\section{Research}

In Germany, each of the 36 university hospitals of psychiatry supports research activities. Additionally, the Max-PlanckSociety has a research institute for psychiatry in Munich.

The Ministry of Education and Research established a number of 'networks of competence in medicine' in 1999, among which were research networks for schizophrenia, depression and suicide, and dementia. In addition, the German Research Council and the Federal Ministry of Research and Education fund mental health research. In the major current research funding lines of the German Research Council, few psychiatric topics are included. A complete list would be beyond the scope of this report. 
The Ministry of Education and Research supports three psychiatric Networks of Excellence and Brain-Net (total funding approximately €66 million for a 5-year period; BrainNet is a collection of clinical data and brain autopsy tissues). It also supports addiction research (€33 million over 19912004; the current emphasis is on the transfer of research results into clinical practice with an additional funding of $€ 9$ million for 2004-07). Smaller-scale research funding is currently being initiated in special research programmes for cognitive science and clinical research.

The German Health Ministry has identified both major depression and nicotine addiction as targets for health intervention, besides type 2 diabetes and breast cancer, among others (Weber, 2006).

\section{Professional organisations}

The DGPPN is the scientific organisation of psychiatrists in Germany (http://www.dgppn.de). Its objectives are to provide $\mathrm{CME}$, to support legislation, administration concerning all aspects of mental disorders, and the development of international relations. Currently, it has more than 3500 members. The DGPPN has developed treatment guidelines for clinical practice. For example, the guidelines for schizophrenia were developed as evidence-based consensus guidelines (S3 level) (Gaebel \& Falkai, 2006).

There are also professional societies for psychiatrists in private practice (Bundesverband Deutscher Nervenärzte, Bundesverband Deutscher Psychiater), senior psychiatrists in hospitals (Bundesdirektorenkonferenz), for practitioners of psychosomatic medicine (Deutsche Gesellschaft für Psychosomatische Medizin und Ärztliche Psychotherapie), and for child and adolescent psychiatry, psychosomatics and psychotherapy (Deutsche Gesellschaft für Kinder- und Jugendpsychiatrie, Psychosomatik und Psychotherapie). In addition, there are many regional and local associations of psychiatrists, plus approximately 30 societies governing special aspects of psychiatry or psychotherapy.

\section{Outlook}

A more extensive report on the current state and trend of mental healthcare in Germany was recently published by Salize et al (2007). Some topics have an international background; these include the development of ICD-11 and DSM-V. Furthermore, the new insights from genetic and neurobiological studies will increasingly be transferred to clinical practice. The integration of neurobiology, social sciences and psychology with psychopathology will clearly become a major issue.
German clinical psychiatry is facing tremendous challenges because of the demographic changes resulting in an increased proportion of older patients and an increasing demand from patients from immigrant families. Clinically, topics like somatic comorbidity (among others, the metabolic syndrome in patients treated with atypical antipsychotics), evidence-based assessment of psychotherapeutic practices (including novel approaches to relate clinical effects of psychotherapy to functional magnetic resonance imaging) and the development of evidence-based therapy guidelines are gaining importance, to name just a few.

\section{References}

Baumann, A. \& Gaebel, W. (2006) Entstigmatisierung seelischer Erkrankungen. Ein nationales Programm. [Destigmatisation of mental disorders. A national programme.] Nervenheilkunde, 25, 69-72.

DAK Gesundheitsreport (2006) See http://www.dak.de/content/filesopen/ Gesundheitsreport_2006.pdf (last accessed 17 April 2007).

Fritze, J., Saß, H. \& Schmauß, M. (2005) Befragung der Fachgesellschaften durch den Sachverständigenrat. Stellungnahme der Deutschen Gesellschaft für Psychiatrie, Psychotherapie und Nervenheilkunde (DGPPN) aus dem Jahre 2001. [Questioning of the societies of medical specialties by the board of experts. Statement from the German Society for Psychiatry, Psychotherapy and Nervous Disorders (DGPPN).] In Die Versorgung psychischer Erkrankungen in Deutschland. Aktuelle Stellungnahmen der DGPPN 2003-2004 (eds M. Berger, J. Fritze, C. Roth-Sackenheim, et al), pp. 83-176. Springer Verlag.

Gaebel, W. \& Falkai, P. (2006) S3 Praxisleitlinien in Psychiatrie und Psychotherapie. Band 1: Behandlungsleitlinie Schizophrenie. [Practice Guidelines in Psychiatry and Psychotherapy. Volume 1: Treatment Guideline for Schizophrenia.] Deutsche Gesellschaft für Psychiatrie, Psychotherapie und Nervenheilkunde. Steinkopff Verlag.

Roth-Sackenheim, C. (2005) Qualifizierte ambulante Versorgung psychisch Erkrankter durch fehlgeleitetete Ressourcenverteilung nur noch Utopie. [Qualified out-patient care of patients with mental disorders only a utopia due to misguided allocation of resources.] In Die Versorgung psychischer Erkrankungen in Deutschland. Aktuelle Stellungnahmen der DGPPN 2003-2004 (eds M. Berger, J. Fritze, C. Roth-Sackenheim, et al), pp. 29-38. Springer Verlag.

Salize, H. J., Rössler, W. \& Becker, T. (2007) Mental healthcare in Germany. Current state and trends. European Archives of Psychiatry and Clinical Neuroscience, 257, 92-103.

Sartorius, N. \& Schulze, H. (2005) Reducing the Stigma of Mental Illness. A Report from a Global Programme of the World Psychiatric Association. Cambridge University Press.

Seeman, M. V. (2005) Psychiatry in the Nazi era. Canadian Journal of Psychiatry, 50, 218-225.

Weber, I. (2006) Nationale Gesundheitsziele zu Depressionen. [National health goals for depression.] Deutsches Ärzteblatt, 103, B1408.

Wittchen, H. U. \& Jacobi, F. (2005) Size and burden of mental disorders in Europe - a critical review and appraisal of 27 studies. European Neuropharmacology, 15, 357-376.

World Health Organization (2005) Mental Health Atlas. Country Profile Germany. WHO. See http://globalatlas.who.int/globalatlas/ predefinedReports/MentalHealth/Files/DE_Mental_Health_Profile.pdf (last accessed 17 April 2007). 